\title{
Epigenetic and Metabolic Alterations that Interfere in Human Development and Predispose the Manifestation of Obesity and Other Metabolic Disorders: A Systematic Review
}

\section{Linda Carla Moraes Lima ${ }^{1}$, Angela Civalsci Cubaski ${ }^{1}$, Mirian Ueda Yamaguchi $^{2}$ and Marcelo Picinin Bernuci ${ }^{2 *}$}

${ }^{1}$ Department of Medicine, Cesumar University (UniCesumar), Maringá, Parana Brazil

${ }^{2}$ Health Promotion Department, Cesumar University (Uni Cesumar), Cesumar Institute of Science, Technology and Innovation (ICETI), Maringa, Paraná,

Brazil

*Corresponding Author: Marcelo Picinin Bernuci, Department of Promotion of Health, Cesumar University (UniCesumar), Cesumar Institute of Science, Technology and Innovation (ICETI), Maringá, Paraná, Brazil.
Received: December 17, 2020

Published: January 21, 2021

(C) All rights are reserved by Marcelo Picinin Bernuci., et al.

\section{Abstract}

Recent studies have demonstrated the multifactorial characteristics of the development of metabolic disorders that have shown the necessity for new research in the area, with the objective of unravelling the factors that could possibly influence critical stages of human development, altering a patient's metabolic programming. This study aims to identify the main elements that endorse the biological incorporation of these events on an intrauterine environment or on the first years of life, assessing the potential epigenetic, endocrinological and metabolic mechanisms responsible for this process. The goal of this analysis is to state which main factors allow broader studies to develop specific intervention models for the prevention of metabolic disorders, particularly obesity. This systematic review was based on the PRISMA-E 2012(Preferred Reporting Items for Systematic Reviews and Meta-Analyses) and registered on PROSPERO (№ CRD42020197344). The research and selection of the articles occurred in June-July 2020 and used the United States National Library of Medicine PubMed - Medline and Cochrane Central Register of Controlled Trials databases, and clinical trials that focused on the analysis of influencing factors on metabolic programming were collected. In this study, we discuss how these elements are capable of influencing critical periods of human development and its potential consequences for the affected individuals, with the objective of identifying possible targets for future interventions. Sixty-two articles were identified and included in this systematic review. Among the selected articles, twelve were directly related to epigenetics, fourteen were related to obesity, sixteen were nutrition related and twelve were focused on diabetes. The data revised showed that stress, excessive weight and maternal malnutrition are potential fetal metabolism modifiers that result in disorders that can predispose to child obesity. It was also demonstrated that gestational diabetes and dyslipidemia are conditions that can influence the fetus' levels of adiposity and that epigenetics can directly alter fetal programming, resulting in significant metabolic alterations, including the predisposition to weight disorders in the child. In conclusion, epigenesis presented itself as an important way for biological incorporation of the heritability of metabolic diseases, through the methylation and deacetylation pathways, becoming an important factor in future studies focusing on possible interventions for the prevention of these disorders.

Keywords: Metabolic Programming; Biological Incorporation; Risk Factors; Metabolic Disorders; Mother-Child Overweight 
Epigenetic and Metabolic Alterations that Interfere in Human Development and Predispose the Manifestation of Obesity and Other Metabolic Disorders: A Systematic Review

\section{Introduction}

Child obesity is one of the most important issues of the present day and a challenge for health-systems worldwide. Overweight is defined as an exaggerated and abnormal accumulation of fat that is potentially harmful to one's health [1]. This condition substantially favors the risk of chronic disease, disabilities, affects quality of life and increases mortality through the association of excess weight as a risk factor for the development of cardiovascular disease, dyslipidemia and insulin resistance [2]. There are many risk factors for developing child obesity, according to the Obesity Management Guidelines of the Brazilian Health Supplementary (2017), such as the following: prematurity, obese parents, early interruption of breast feeding, diabetic mothers, small-for-gestational-age (SGA) newborns, large-for-gestational-age (LGA) newborns, erroneous food introduction and the consumption of meals containing high levels of sugar and fat during early childhood. Children that show an elevated body mass index (BMI), accelerated and exaggerated weight gain in their first months have higher chances of becoming overweight [3].

The child obesity rate rose considerably among children aged from five to nine years during the 1989-2009 time period. The percentage of overweight boys in that age group rose from $13.8 \%$ in 1989 to $51.4 \%$ in 2009; the percentage of overweight girls belonging to the same group rose from $10.4 \%$ to $43.8 \%$ during the same time interval [4]. In 2016, approximately 340 million children and adolescents aged between five and nineteen were overweight [1]. This significant impact justifies the importance of understanding the development of this process and the potential modifiable risk factors, so that specific interventions can be elaborated. Obesity has a multifactorial etiology and is defined as a polygenic condition, the combination of a group of genes that favors adiposity due to its activity on genetic components; its modification of microorganisms that influence energy metabolism, degrees of inflammation and bowel alterations; the endocrinological disorders associating obesity to conditions such as hypercortisolism, hypoparathyroidism, hyperparathyroidism, growth hormone deficiency; neurological and sleep disorders [4].

In addition to these factors, the epigenetic modulations also present considerable relevance for child obesity and, possibly, for overweight in adults and adolescents. There is current evidence that sustains the idea that there are processes through which the initial life factors can influence the child's health. This concept is named programming and it originated from a great number of epidemiological and experimental observations. The concept of Developmental Origins of Health and Disease (DOHaD), also known as fetal programming, originated initially as an explanation for a definite response generated in an organism against certain expositions during critical periods of human development. The concept of programming was then improved and defined as the process through which the pre-conceptional environment, intrauterine environment and early-childhood longitudinality shapes the physiological control and the homeostasis of the human organism [5].

Recent evidence has pointed to a significant impact of certain early exposures in life - for example: maternal obesity, diabetes, perinatal and neonatal malnutrition - on the child's metabolic risk, creating a transgenerational amplification of metabolic alterations. This epigenomic programming is widely established in the intrauterine period, and is specifically sensitive to prenatal stress factors, resulting in potential singular mutations during one's lifetime, thus influencing the health-disease process [6]. Considering all possible metabolic alterations that can be created through epigenetics and comprehending the existence of a clear relationship with the development of child obesity through influences in embrionary life and early childhood (where the involvement of epigenetic modifications - DNA methylation, histone tails and microRNA modifications - are evidently more related to the development of obesity [7] it is necessary to study and elucidate which are the main influencing factors of this process, with the aim of understanding how to identify successful interventions.

Regarding the formation process of this metabolic programming, the maternal influences are fundamental. Through understanding that preconceptional, gestational and postgestational factors can create alterations or adaptations in the child's metabolic profile, it is possible to comprehend the predisposition to certain diseases such as diabetes, obesity and metabolic syndrome, among others that can be presented by the child. Based on that information, it is understood that the mother's nutritional state, the intrauterine environment, the feto-placental unit development and dietary intake, affect not only the maternal metabolic modification during pregnancy but also the capacity of programming the fetus [8]. Therefore, the main goal of the present study is to analyze the potential environmental and genetic influences that affect preg-

Citation: Marcelo Picinin Bernuci., et al. "Epigenetic and Metabolic Alterations that Interfere in Human Development and Predispose the Manifestation of Obesity and Other Metabolic Disorders: A Systematic Review". Acta Scientific Nutritional Health 5.2 (2021): 107-119. 
nant individuals and result in alterations on human development that can happen from the embrionary period to early childhood, making children susceptible to metabolic disorders, especially obesity.

\section{Materials and Methods}

This article is a systematic review, written based on the PRISMA-E 2012(Preferred Reporting Items for Systematic Reviews and Meta-Analyses) report guide [9]. It was registered on PROSPERO (№ CRD42020197344). The methods are schematized in Figure 1.

\section{Database and research methods}

The research was conducted in the United States National Library of Medicine PubMed - Medline and Cochrane Central Register of Controlled Trials electronic databases between the period of June $01^{\text {st }}$ - August $05^{\text {th }} 2020$. The following describers were used in the research: "epigenetics and obesity", "maternal influences related to obesity" and "maternal influences and metabolic programming".

\section{Eligibility criteria}

The PICO (Population, Intervention, Comparison and Outcomes) system was followed, described in table 1.

\begin{tabular}{|l|c|}
\hline Population & $\begin{array}{c}\text { Pregnant women presenting gestational } \\
\text { diabetes mellitus or overweight. }\end{array}$ \\
\hline Intervention & $\begin{array}{c}\text { Lifestyle changes, physical exercise, dietary } \\
\text { supplementation and pharmacological } \\
\text { treatment for gestational diabetes mellitus. }\end{array}$ \\
\hline Comparison & $\begin{array}{c}\text { Obese pregnant women with comorbidities } \\
\text { compared to healthy pregnant women. }\end{array}$ \\
\hline Outcomes & $\begin{array}{c}\text { Overweight, diabetes and supplementation } \\
\text { alter the child's metabolism and influence it to } \\
\text { develop obesity. }\end{array}$ \\
\hline
\end{tabular}

Table 1: Detailed eligibility criteria following the PICO system. Source: Authors (2020).

Clinical trials, randomized clinical trials, books and documents were included. These were included based on four questions of the main analysis: Are there embrionary development factors that corroborate for the development of dyslipidemia in the future? What are the possible genetic and epigenetic factors that can interfere in embrionary development? How do these factors, including environmental influence, endorse the development of metabolic dis- orders, particularly obesity? In which phases do these determinant factors act? From this were selected articles published in the last 10 years, with no language restriction. Excluded: doubled articles, articles published before 2010 , high risk of bias and systematic reviews.

\section{Data extraction}

The article extraction was done in duplicate by the two main authors and stored in a digital table in Excel.

\section{Risk of bias assessment}

The following categories were assessed: bliding of the participants, professionals and evaluators; creation of random sequences; concealment of allocation; uncomplete conclusions and selective reports or other potentially biased sources. The risk of bias determined for each domain was: (1) high risk; (2) unknown risk; (3) low risk.

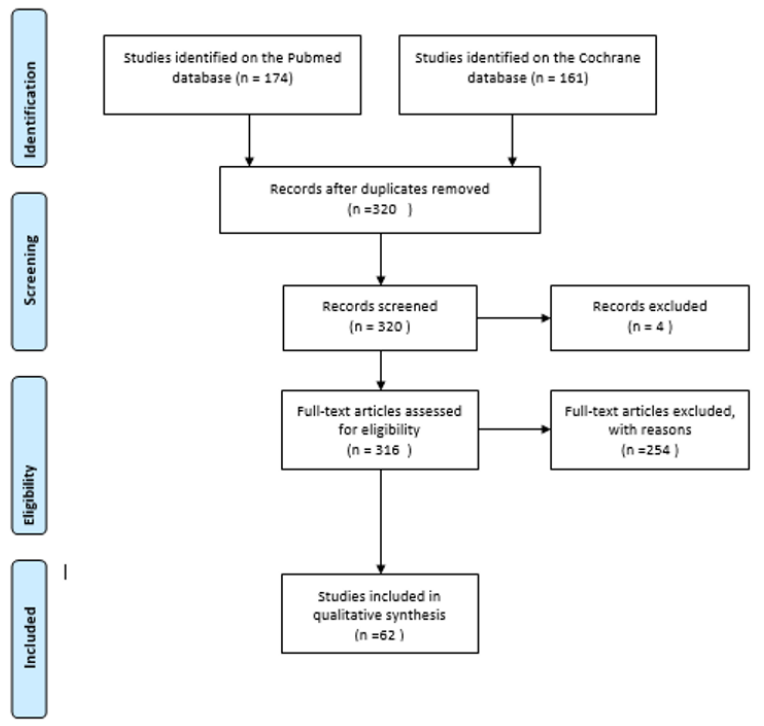

Figure 1: Flow diagram showing the identification, screening, eligibility and inclusion of the articles. Source: Authors (2020).

\section{Results and Discussion}

Sixty-two articles were identified and included in this systematic review. There was great heterogeneity in the studies regarding the size of samples, length and assessing methods. Four main fac- 
tors were determined following the analysis of the articles, these being: epigenetics, nutrition, obesity and diabetes. Among the selected articles, twelve were directly related to epigenetics, fourteen were related to obesity, sixteen were nutrition related and twelve were focused on diabetes. In the end, only the most important studies were selected, which are presented in table 2 , where a brief de- scription of the selected articles is directly related to the previously mentioned topics.

\section{Epigenetics}

According to studies, the excessive calorie storage through fat was of extreme importance for our ancestors, it guaranteed higher

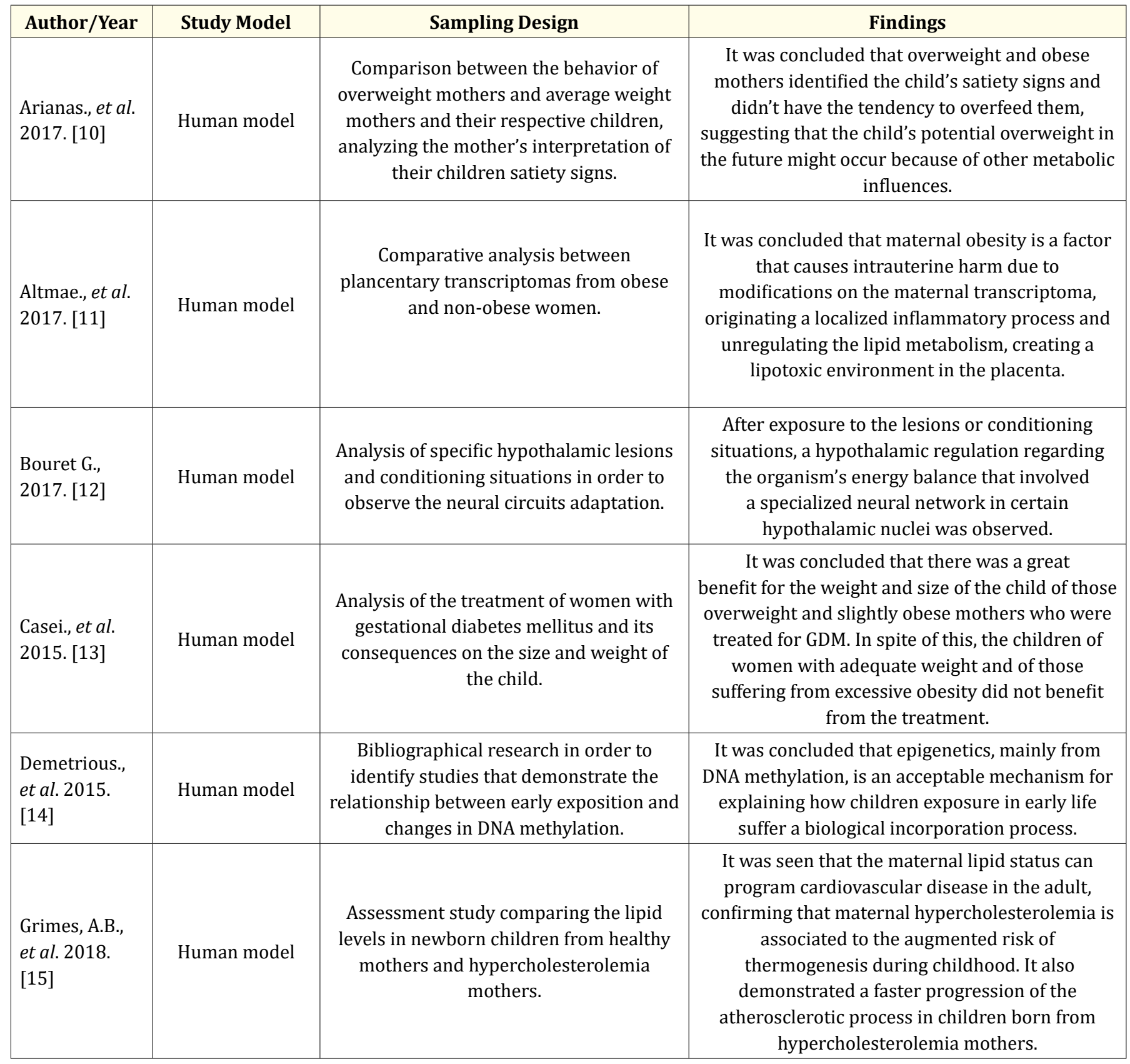

Citation: Marcelo Picinin Bernuci., et al. "Epigenetic and Metabolic Alterations that Interfere in Human Development and Predispose the Manifestation of Obesity and Other Metabolic Disorders: A Systematic Review". Acta Scientific Nutritional Health 5.2 (2021): 107-119. 


\begin{tabular}{|c|c|c|c|}
\hline $\begin{array}{l}\text { Haschke, F.., } \\
\text { et al. } 2019 . \\
{[16]}\end{array}$ & Human model & $\begin{array}{l}\text { The study longitudinally followed the } \\
\text { anthropometric evolution of children that } \\
\text { presented with previous morbidity risk, } \\
\text { associating health progression to the use } \\
\text { of exclusive breastfeeding or just } \\
\text { formulas. }\end{array}$ & $\begin{array}{l}\text { At the end of the study, it was found that children } \\
\text { that received exclusive breastfeeding during a } \\
4 \text { - } 6 \text { month period or those who received infant } \\
\text { formulas with low protein concentrations had a } \\
\text { slower development in comparison to children } \\
\text { that were fed with high protein concentration } \\
\text { formulas. The anthropometric measurements } \\
\text { during the } 5 \text { - } 8 \text { years of age period demonstrated } \\
\text { that breastfeeding and low-protein infant } \\
\text { formulas are related to lower weight gain and fat } \\
\text { storage in the future. }\end{array}$ \\
\hline $\begin{array}{l}\text { Hawkins., et al. } \\
\text { 2017. [17] }\end{array}$ & Human model & $\begin{array}{l}\text { Comparative study among adequate, } \\
\text { overweight and GDM women. }\end{array}$ & $\begin{array}{l}\text { It was proved that adequate weight women that } \\
\text { suffered from GDM have greater probabilities of } \\
\text { presenting weight gain after pregnancy and of } \\
\text { giving birth to overweight children. Besides that, } \\
\text { GDM was associated with higher risks of child } \\
\text { obesity and cardiovascular disease. }\end{array}$ \\
\hline $\begin{array}{l}\text { Lillycrop, K... } \\
\text { et al. } 2017 . \\
{[18]}\end{array}$ & Human model & $\begin{array}{l}\text { Analysis of the long non-coding RNA } \\
\text { ANRIL methylation levels and their } \\
\text { relationship with the probable risk of } \\
\text { developing obesity. }\end{array}$ & $\begin{array}{l}\text { The association between perinatal methylation } \\
\text { in important loci for the ANRIL gene function } \\
\text { and higher prevalence of child obesity rates were } \\
\text { proved. This statement offers support for the } \\
\text { assumption that epigenetic processes are } \\
\text { important during fetal programming } \\
\text { development. }\end{array}$ \\
\hline $\begin{array}{l}\text { Litwin., et al. } \\
\text { 2019. [19] }\end{array}$ & Human model & $\begin{array}{l}\text { Observational study conducted on pairs of } \\
\text { mothers and children in which } \\
\text { mothers that presented normal weight } \\
\text { during pregnancy were compared to } \\
\text { mothers that suffered from overweight } \\
\text { and GDM. }\end{array}$ & $\begin{array}{l}\text { It was demonstrated that weight gain associated } \\
\text { with GDM directly affects the child's weight gain, } \\
\text { although this relationship is only detectable in } \\
\text { individuals that present }>30 \mathrm{~kg} / \mathrm{m} 2 \text { BMI. It was } \\
\text { proved that the higher incidence of overweight } \\
\text { in children from mothers that suffered from GDM } \\
\text { during pregnancy is due to a failure in glycemic } \\
\text { regulation. }\end{array}$ \\
\hline $\begin{array}{l}\text { Mustila., et al, } \\
\text { 2018. [21] }\end{array}$ & Human model & $\begin{array}{c}\text { Interventional study applied to pregnant } \\
\text { women with high risk of GDM and } \\
\text { overweight women with the goal of } \\
\text { preventing child obesity. }\end{array}$ & $\begin{array}{l}\text { The research showed that early interventions in } \\
\text { pregnant women with high risk of } \\
\text { developing GDM helps to prevent that condition } \\
\text { and consequently reduces the chances of } \\
\text { overweight children. }\end{array}$ \\
\hline
\end{tabular}




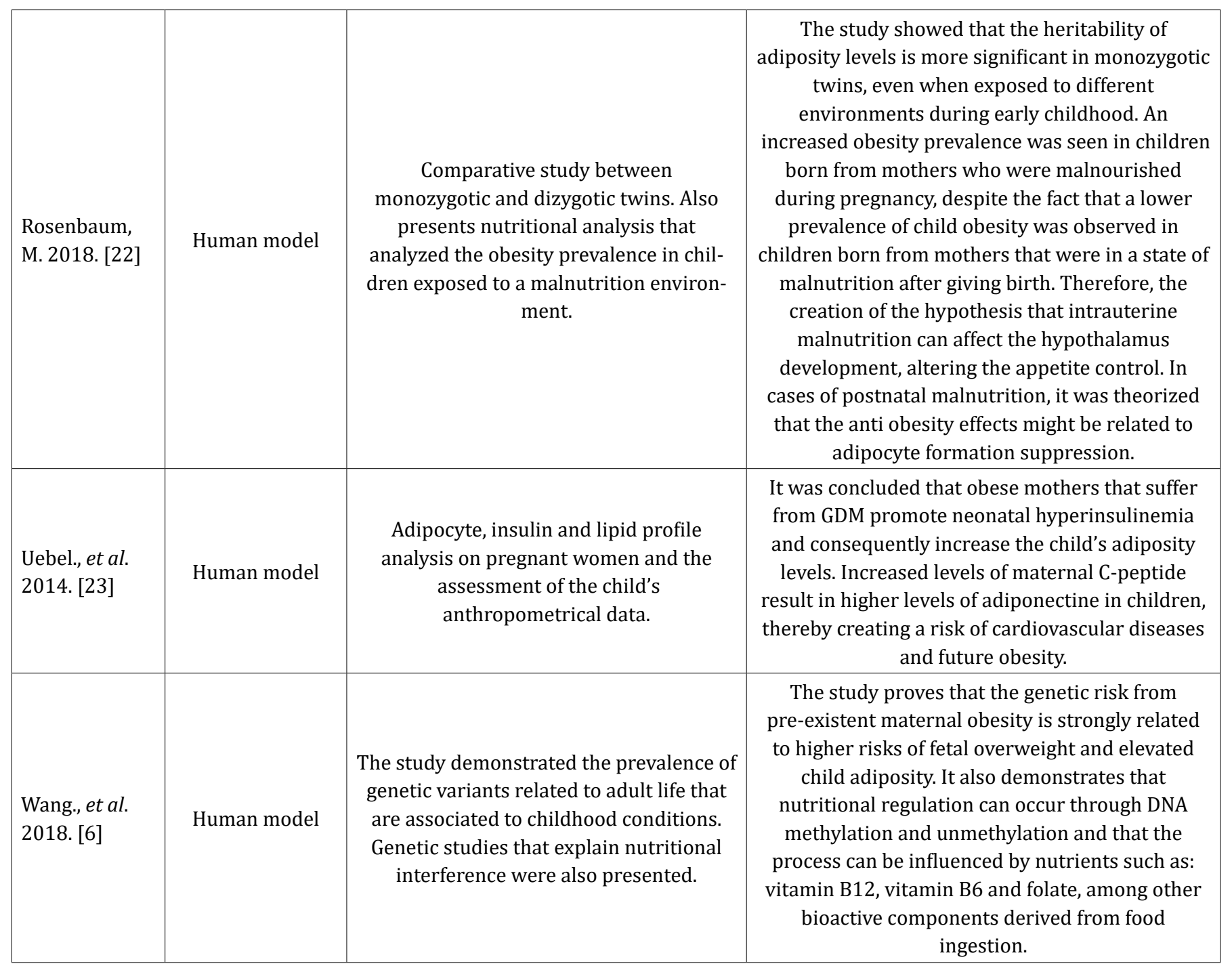

Table 2: Brief description of the main points associated to the four main topics chosen on the present systematic review. Source: Authors (2020).

chances of survival during long periods of calorie restriction and created a reproductive advantage through the increment of female fertility, allowing them to have greater breastfeeding capacities. Therefore, it is possible that through natural selection, the human genome was enhanced with genes that favor the storage of adipose tissue. In the majority of cases (except for the cases where rare mutations on a single gene are able to greatly increase body fat), body fat has a quantitative character that shows the interaction between development and associated environmental factors to the inherited genome. Cohort studies that analyzed twins indicate that the heritability rate of body fat and its distribution in adult life is of $50-80 \%$. Research has already identified significant genetic influence, around $30 \%$, on the rest metabolic rate, food preferences, eating behavior and alterations in energy consumption that occur in response to a nutritional excess. The genetic influence was also evident in studies conducted on twins, in which the heritability calculation assumes that members of each pair (monozygotic or dizygotic) are raised in the same environment and that the level 
Epigenetic and Metabolic Alterations that Interfere in Human Development and Predispose the Manifestation of Obesity and Other Metabolic Disorders: A Systematic Review

of similarity is greater among monozygotic twins due to a greater genetic similarity [22].

Epigenetic mechanisms are essential for normal human development and play a great role in complex human diseases [24-26]. Animal and human models show that the intrauterine period is susceptible to the establishment of epigenetic variability [27-31], and consequently influences the risk of future development of various deseases [6]. Epigenetics is extremely important for understanding obesity, through the comprehension of the existence of epigenetic interference in the predisposition of obesity. It was possible to analyze the intrauterine environment effects, the histone acetylation process and microRNA expression, which are of great importance for obesity gene expression. Related to this process, the increase in DNA methylation will decrease the transcription of relevant genes and demonstrate that it can be influenced by parental obesity, maternal diet, gestational diabetes and the use of medication during pregnancy. Research showed that the loss of histone demethylaze is responsible for the manifestation of obesity through decreased expression of PPAR $\alpha$ and UCP1 and the deacethylation of GLUT4 histone tail that causes a deficiency in the use and transportation of serum glucose [22].

In a different study, evidence also favored the confirmation of epigenetic interference in human development. Here, the differences in interindividual DNA methylation on distinct human tissues associated with child obesity were examined and a new association between $\mathrm{CpG}$ methylation levels at birth inside the long noncoding RNA ANRIL (coded at CDKN2A) and child obesity at the age of 6 years. A relationship between ANRIL methylation and adiposity was also seen in three additional populations: in the analysis of ethnically different newborns, in adolescent's peripheral blood and in adult adipose tissue. Finally, CpG methylation was associated with ANRIL expression in vivo: CpG's in vivo mutagenesis inhibits ANRIL-promoter activity. Hence, the results demonstrated that perinatal methylation in relevant loci for that gene's function can be a fundamental posterior adiposity marker, aiding the epigenetic processes in the development of long-term consequences for human life [18].

\section{Nutrition}

It is widely known that presently, nutrition is a biological science with physiological, genomic, social, medical and environmental components. Through time, researchers gathered important ev- idence that food ingestion, from preconception, afterbirth and even in later years was essential for the health-disease process throughout life and for subsequent generations [32]. The process in which there are phenotypical changes, with no DNA sequence alterations but alterations in gene expression is known as epigenetics. Nutritional epigenetics defines nutrition as one of the main environmental factors that has a continuous interaction with the individual's health, being capable of influencing epigenetic changes and consequently alterations in health development [33].

Epigenetic regulation happens through methylation and demethylation processes that alter the DNA conformation, and this regulation is dependent or influenced by nutrients such as folate, betaine, vitamin B12, vitamin B6, iron, selenium and methionine, among other bioactive components obtained from food ingestion [26]. Therefore, evidence is becoming stronger and pointing towards a relevant relationship between eating regulation and gene expression with multiple health consequences [6].

Prenatal malnutrition is the reflex of maternal malnutrition or a fetal nutritional support malfunction, usually originating in failures in the placenta. From that, the hypothesis that malnutrition during intrauterine life can affect hypothalamic development, altering the pathways that control appetite, was created [22]. The hypothesis that deficient nutrition during the perinatal development period creates a "economical phenotype", in which the individual adapts to a certain environment where food is scarce and develops a lower stature, a lower metabolic rate and demonstrates less activities in order to conserve energy. If the same individuals were posteriorly exposed to an environment with a richer nutritional supply, they would have a greater risk of developing type 2 diabetes, obesity and other metabolic disorders due to an incongruence between the real and idealized environment. The concept of perinatal programming derived from nutrition was associated to other nutrional stimuli, including maternal overnutrition and/or afterbirth overnutrition [12].

There is growing evidence that the development programming of the neurological pathways involved in energy metabolism through the perinatal environment is a potential cause of obesity and other metabolic alterations, one of them being diabetes. A special component of this neural pathway contains a neuron network located in the hypothalamus. Experiments that were based on physical lesions in specific hypothalamic regions and, more re- 
Epigenetic and Metabolic Alterations that Interfere in Human Development and Predispose the Manifestation of Obesity and Other Metabolic Disorders: A Systematic Review

cently, conditioning studies using directioning strategies of specific neuron genes, found that hypothalamic regulation of energy balance involves a neural network containing special neurons located at the arcuate nucleus (ARC), the ventromedial nucleus (VMH), the dorsomedial nucleus (DMH), the paraventricular nucleus (PVN) and the lateral hypothalamic area (LHA) [12].

Long term screening studies were conducted, assessing smallfor-gestational-age children that showed clinical signs of prenatal malnutrition; at the end of the study, it was reported that even after the adult adiposity levels were corrected, the birth weight was strongly related to the morbidity incidence associated with obesity, including type 2 diabetes, arterial hypertension, stroke and cardiovascular disease in adult life. This association statement reinforces the preconception of interaction between prenatal environment and life-long development, influencing the pancreatic beta cells and the function of other organs related to the energy and cardiovascular regulation processes in the adult, such as the hypothalamus, liver and kidneys. Thus, the main hypothesis would be that the cardiovascular, endocrinological and metabolic basis that explains the development of conditions related to adiposity in adults originates through a fetal adaptive process in response to malnutrition, particularly when the calorie access in the environment where the child is born is no longer limited [22].

Another nutritional risk factor that is associated with a child's future risk is hypercholesterolemia, which is a risk factor for the development of atherosclerosis that usually happens in adult life. However, evidence shows that the atherosclerotic process can start during uterine development. The first suspicion that maternal lipid profile has the capacity to program cardiovascular disease in the adult began from observations in which maternal hypercholesterolemia, even when restricted to the pregnancy period, was strongly related to an increase in size of the fatty stripes on the fetal aorta. It was also stated that the progression of atherosclerosis is significantly faster in children born from hypercholesterolemic mothers. Yet, comprehension of the mechanisms responsible for the effects of maternal dyslipidemia on fetal development and atherosclerosis risk is still incomplete and needs more research. Observational studies have already proved the harmful effect of maternal hyperlipidemia on metabolic programming; the control of this condition is essential during pregnancy. The baseline treatment is composed of multifactorial actions including adequate diet, exercise and weight control. That is because the pharmacological treatment of dyslipidemia during pregnancy requires great caution [15].

A well-established point is that nutrition during the first 1,000 days of life may have a long-time influence on growth, metabolism and health during adult life. Some studies observed that children that are exclusively breastfed for a period of $4-6$ months or the ones that receive infant formulas with a low protein concentration have a slower growth rate in comparison to children fed with high protein concentration infant formulas during the first 3 years of life. Measurements of bodily compositions conducted with 5 8-year-old children showed that breastfeeding and low protein concentration infant formulas are related with a higher adiposity gain [16].

\section{Gestational diabetes}

Child obesity can be related to the prenatal environment, presence of GDM, diet and maternal physical activities. Thus, studies that assess interventions in these aspects during pregnancy evaluate how influential maternal metabolic factors are on the child's metabolic alterations.

Gestational diabetes is defined as the diabetes first diagnosed during pregnancy, more specifically during the 24-28-week pregnancy period and can predispose risks to both mother and child [17]. It is possible to associate GDM to fetal over nutrition because there is an increase in local glucose, lypogenesis, fetal hyperinsulinemia and consequently fetal macrossomy (birth weight greater than 4 kilograms) [22].

Through epigenetic alterations caused by GDM, children born from mothers suffering from this condition have greater chances of developing metabolic diseases or becoming obese adults. On a study conducted with obese pregnant patients it was possible to observe that children born from mothers that were overweight and suffered from GDM had alterations in DNA methylation. This alteration suffered great reduction when the diabetes treatment was initiated, proving the direct influence of maternal metabolic modulation on the child's epigenetic development [18].

In a study conducted with women that suffered from high risk GDM or with BMI $\geq 30 \mathrm{~kg} / \mathrm{m}^{2}$, it was observed that children exposed to a maternal environment with gestational diabetes or with BMI $\geq 30 \mathrm{~kg} / \mathrm{m}^{2}$ have greater overweight rates when compared to chil- 
dren born to mothers with an adequate glycemic control. Around $20 \%$ of the assessed children presented with excessive weight and $14 \%$ were defined as obese [19]. Another study that associated interventions with the goal of preventing GDM showed that adequate care resulted in lesser incidence of diabetes during pregnancy. That being so, low glucose levels and lower risk of developing GDM is related to a smaller chance of child weight gain and lower risk of developing type 2 diabetes [21].

Children of mothers that suffer from GDM have greater fat and insulin secretion levels until 5 - 10 years of age regardless of the individual's BMI and are more likely to develop obesity, type 2 diabetes mellitus and cardiovascular disease in the future [17]. This happens because of a compensation mechanism existent on pancreatic beta cells that increase insulin secretion in order to compensate the greater concentration of glucose in the bloodstream of a mother that suffers from GDM. Increased insulin secretion raises fetal adiposity.

A large number of pregnant women that suffer from GDM are also overweight or obese, and that makes it difficult to distinguish the cause of the metabolic dysfunction that makes children overweight or obese. In these cases, it is not known if the child is overweight due to maternal metabolic consequences or because of genetic inheritance [22].

\section{Obesity}

Body fat reflects interactions with the environment, life habits, genetic heritage and human development conditions related to epigenetics. Various studies have tried to prove the association between fetal exposure to maternal obesity during pregnancy and its consequences on children's weight gain. Women that were obese during pregnancy presented 2 - 5 times higher incidence of largefor-gestational-age children. Related to that is the fact that children born of mothers that underwent bariatric surgery and lost weight, themselves presented children with reduced body fat [22].

Pre-pregnancy BMI can be associated with child body fat gain, although weight gain was only evident in children born of mothers with $\mathrm{BMI} \geq 30 \mathrm{~kg} / \mathrm{m}^{2}$ [19].

Women that were obese before pregnancy and had GDM were more likely to present children with hyperinsulinemia and an increase in adiposity levels until the sixth week. This study also reports that the relationship between hyperinsulinemia and the impact of intrauterine hyperinsulinemia in raising fetal adipose tissue fat disappears during the first year of life. Associated with this insulin and glucose level dysfunction, the increase in maternal C-peptide raises adiponectine levels favoring the growth of preperitoneal adipose (PPA) tissue in newborns. Consequently, there is a greater risk of child obesity and future cardiovascular disease (2014). Besides the fact that maternal obesity stimulates high insulin levels and hormones like adiponectine suggesting an adipocyte and leptine increase, despite presenting low levels of IGF-1, suggesting that the exacerbated growth occurred because of insulin excess. Despite this, the elevated fetal growth is not related to adult consequences, but from having an accelerated growth rate due to hormone concentration [20].

Cholesterol metabolism is essential for fetal growth, but pregnant women with any dyslipidemia associated with weight excess can be a predisposing factor for fetal size deregulation and future obesity [15].

Studies also report the dysfunction existent in the placental transcriptome that promote adverse effects due to deregulation in molecular pathways responsible for the development of the placenta in obese mothers. In this way, it is possible to observe the unregulated lipid metabolism that creates a lipotoxic environment in the placenta, with augmented oxidative and inflammatory stress markers associating them to metabolic disorders such as hyperlipidemia and atherosclerosis [11]. Inflammation derived from maternal obesity is also associated to changes in fetal mesenchymal cells, resulting in newborn muscular cell alterations, increasing the fetal size. This fetal growth mechanism is not related to glucose metabolism deregulation [13].

Children with obese parents are four times more likely to develop obesity during early childhood. Mothers predisposed to weight gain due to genetic risk, environmental exposure to poor diets or a sedentary lifestyle will have children exposed to these same conditions, raising the risk for the development of obesity [17]. Contrastingly, obese mothers don't have the tendency to overfeed their children during the first months of life, which suggest that other factors could add to the ones previously mentioned and predispose excessive weight gain [10].

Figure 2 shows the relationship between maternal metabolic alterations, maternal overweight, gestational diabetes mellitus (GDM) and consequences for the affected children. 


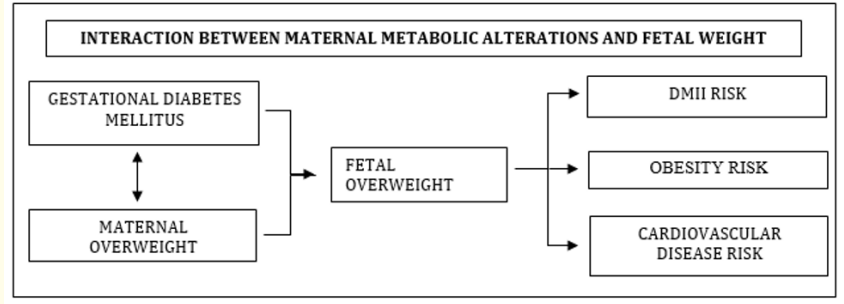

Figure 2: Relationship between gestational diabetes mellitus and maternal overweight. Source: Authors (2020).

The goal of this systematic review was to analyze the main factors that influence human development, identifying the factors that can interfere in critical periods of this process, either in the preconception phase, pregnancy or afterbirth, bearing in mind that the embrionary, prenatal and perinatal periods are highly plastic periods and that is why the fetus is sensitive to environmental and intrauterine alterations. The main factors that were identified through the analysis include paternal stimuli, events that happen in the intrauterine environment and afterbirth environmental stimuli, in a way that the combination of these factors affect metabolic programming. These factors are demonstrated in figure 3.

Regarding the epigenetic analysis, despite the heterogeneity of the presented studies, sample sizes, exposition and results, the final conclusions support the hypothesis that overweight and obesity in childhood are associated to epigenetic alterations, endorsing the preconception of biological incorporation. This proves the hypothesis that the epigenome can influence obesity patterns, either because of direct influences of the involved genes in the metabolic pathways that predispose to future obesity or reflected in one or more factors that influence both DNA methylation and the patterns responsible for obesity in the afterbirth period and nutrition during early childhood [14].

After analyzing all the studies related to nutrition, we observed that a nutritional conduct on critical periods of human development have a strong influence over the affected child's metabolic programming, either through epigenetics or endocrinological pathways. This demonstrates the need for attention and detailed research, specially focused on breastfeeding and low-fat diets as nutritional interventions that could possibly help pregnant women avoid these alterations on their offspring.
Metabolic disorders associated to obesity have been important to the identification of factors that influence children to become obese. Therefore, besides dietetic and behavior factors, it is possible to associate child obesity to the metabolic influences present during the time spent in the intrauterus environment. Maternal overweight can directly or indirectly influence the fetal metabolism, predisposing the individual to a great number of inflammatory alterations on lipid, glucose and hormone metabolism that endorse the accumulation of adipocytes and weight gain during pregnancy or early childhood.

Maternal weight variation is also a risk factor for the development of gestational diabetes mellitus that is defined as a failure in the glucose regulation during pregnancy. This maternal organism alteration also creates changes that favor fetal weight gain. Hyperglycemia and insulin resistance are conditions that alter the fetal nutrition and promote a greater growth rate, resulting in large for gestational age (LGA) newborn that predispose the development of cardio metabolic disorders on the mother and offspring over the years.

It was possible to confirm the previously established multifactorial hypothesis that involves the development of metabolic disorders. The relationship between epigenetics, maternal nutrition, preexistent metabolic disorders in pregnant women, stress among other topics mentioned on this review presented capable of directly influencing fetal adaptation, modulating one's metabolic response. We were able to confirm, through the analysis of child obesity development, the interference of the maternal organism and environmental factors on this process, which surpass the commonly accepted hypothesis that bad eating habits and sedentarism are the only responsible.

\section{Conclusion}

In conclusion, epigenetic presented itself as an important way for biological incorporation of the heritability of metabolic diseases, through the methylation and deacetylation pathways, becoming an important factor in future studies focusing on possible interventions for the prevention of these disorders. The nutrition factor also appeared to be an influencer that endorse the modulation of fetal and child response, either on the intrauterine period where maternal malnutrition or over nutrition can alter the phenotype developed through neurological and endocrinological pathways or on the first years of life, a period when the nutritional support of- 


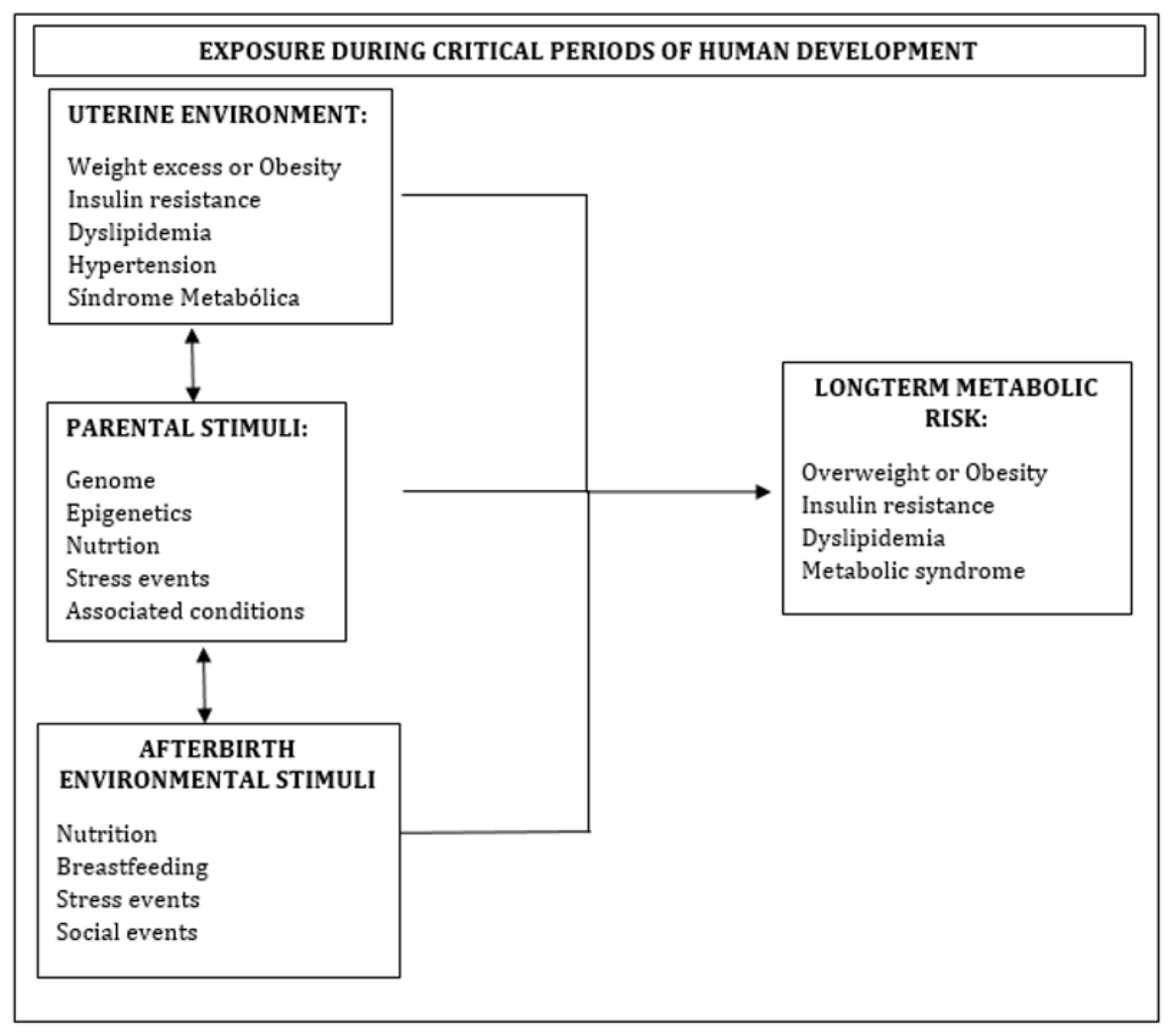

Figure 3: Summary of the main factors that affect human development. Source: Authors (2020).

fered by the environment shapes an individual's energetic profile. Maternal overweight appears to have great influence on the offspring future weight, through promotion of metabolic alterations on fetal development mainly due to a lipid metabolism disequilibrium. At last, gestational diabetes mellitus was also identified as a direct influence on fetal metabolism due to high maternal blood glucose levels that creates an endocrinological disequilibrium. When identifying the potential risk factors that affect critical stages of human development and influence on the appearance of metabolic disorders, obesity in particular, it is important to understand the necessity of new prevention politics. We understood that investments on new research areas specialized on the main topics presented in this review are fundamental, in order to create specific multi factorial intervention protocols that cover the whole process, from the preconceptional period to post natal period.

\section{Acknowledgements}

This research was possible thanks to the financial support of Araucaria Foundation, through the Institutional Program of Scientific Initiation and Technological Development and Innovation Scholarships (PIBIC and PIBIT) and the Instituto Cesumar de Ciência, Tecnologia e Inovação (ICETI), Maringa, Paraná, Brazil.

\section{Conflict of Interest}

The authors declare no conflict of interest.

\section{Bibliography}

1. dos Santos Gabriela Martins and Carlos Alberto Figueiredo da Silva. "Obesidade infantil e seus impactos psicológicos e sociais". Intercontinental Journal on Physical Education 2.3 (2020): 0-1. 
2. Lobato Jackeline Christiane Pinto., et al. "Programação fetal e alterações metabólicas em escolares: metodologia de um estudo caso-controle". Revista Brasileira de Epidemiologia 19 (2016): 52-62.

3. Camargos Ana Cristina Resende., et al. "Prevalência de sobrepeso e de obesidade no primeiro ano de vida nas Estratégias Saúde da Família". Cadernos Saúde Coletiva 27.1 (2019): 3238.

4. Nogueira-de-Almeida Carlos Alberto., et al. "Classificação da obesidade infantil". Medicina (Ribeirao Preto Online) 51.2 (2018): 138-152.

5. de Gusmao Correia M L., et al. "Developmental origins of health and disease: experimental and human evidence of fetal programming for metabolic syndrome". Journal of Human Hypertension 26.7 (2012): 405-419.

6. WANG G., et al. "Fatores de preconceito e pré-natal e risco metabólico”. In: Halfon N., Forrest C., Lerner R., Faustman E. (eds) Handbook of Life Course Health Development. Springer, Cham (2018): 47-59.

7. Lopomo Angela E Burgio and Lucia Migliore. "Epigenetics of obesity". Progress in Molecular Biology and Translational Science Academic Press 140 (2016): 151-184.

8. Lima Rafael Silva. "Avaliação e associação dos parâmetros metabólicos, inflamatórios e epigenéticos na obesidade infantil" (2019).

9. Welch Vivian., et al. "Extending the PRISMA statement to equity-focused systematic reviews (PRISMA-E 2012): explanation and elaboration". Journal of Clinical Epidemiology 70 (2016): 68-89.

10. Arianas Evanthia A., et al. "Maternal weight status and responsiveness to preterm infant behavioral cues during feeding". BMC Pregnancy and Childbirth 17.1 (2017): 113.

11. Altmäe Signe., et al. "Maternal pre-pregnancy obesity is a: sociated with altered placental transcriptome". PloS One 12. (2017): e0169223.

12. Bouret Sebastien G. "Development of hypothalamic circuits that control food intake and energy balance". Appetite and Food Intake: Central Control (2017): 135-154.
13. Casey Brian M., et al. "Does maternal BMI influence treatment effect in women with mild gestational diabetes?". American Journal of Perinatology 32.1 (2015): 93.

14. Demetriou Christiana A., et al. "Biological embedding of early-life exposures and disease risk in humans: a role for DNA methylation". European Journal of Clinical Investigation 45.3 (2015): 303-332.

15. Grimes Sarah B and Robert Wild. "Effect of pregnancy on lipid metabolism and lipoprotein levels". Endotext MDText. com, Inc., (2018).

16. Haschke Ferdinand., et al. "Early-life nutrition, growth trajectories, and long-term outcome". Human Milk: Composition, Clinical Benefits and Future Opportunities 90 (2019): 107-120.

17. Hawkins Summer Sherburne., et al. "Early in the life course: Time for obesity prevention". Handbook of Life Course Health Development Springer, Cham (2018): 169-196.

18. Lillycrop Karen., et al. "ANRIL promoter DNA methylation: a perinatal marker for later adiposity". EBioMedicine 19 (2017): 60-72.

19. Litwin L., et al. "Transgenerational effects of maternal obesity and gestational diabetes on offspring body composition and left ventricle mass: the Finnish Gestational Diabetes Prevention Study (RADIEL) 6-year follow-up". Diabetic Medicine 37.1 (2020): 147-156.

20. Larnkjær Anni., et al. "The influence of maternal obesity and breastfeeding on infant appetite-and growth-related hormone concentrations: the SKOT cohort studies". Hormone Research in Paediatrics 90.1 (2018): 28-38.

21. Mustila Taina., et al. "A pragmatic controlled trial to prevent childhood obesity within a risk group at maternity and child health-care clinics: results up to six years of age (the VACOPP study)". BMC Pediatrics 18.1 (2018): 89.

22. Rosenbaum Michael. "Special Considerations Relevant to Pediatric Obesity". Endotext (2018).

23. Uebel Kirsten., et al. "Effect of maternal obesity with and without gestational diabetes on offspring subcutaneous and preperitoneal adipose tissue development from birth up to year1". BMC Pregnancy and Childbirth 14.1 (2014): 138. 
24. O’Neill Rachel J., et al. "Maternal methyl supplemented diets and effects on offspring health". Frontiers in Genetics 5 (2014): 289.

25. Reynolds Rebecca M., et al. "Maternal obesity during pregnancy and premature mortality from cardiovascular event in adult offspring: follow-up of 1323275 person years". BMJ 347 (2013): f4539.

26. Dolinoy Dana C., et al. "Epigenetic gene regulation: linking early developmental environment to adult disease". Reproductive Toxicology 23.3 (2007): 297-307.

27. Heijmans Bastiaan T., et al. "Persistent epigenetic differences associated with prenatal exposure to famine in humans". Proceedings of the National Academy of Sciences 105.44 (2008): 17046-17049.

28. DeAnn Cook Jennifer., et al. "Identification of a sensitive period for developmental programming that increases risk for uterine leiomyoma in Eker rats". Reproductive Sciences 14.2 (2007): 121-136.

29. Tang Wan-yee., et al. "Neonatal Exposure to Estradiol/Bisphenol A Alters Promoter Methylation and Expression of Nsbp1 and Hpcal1 Genes and Transcriptional Programs of Dnmt3a/b and Mbd2/4 in the RatProstate Gland Throughout Life". Endocrinology 153.1 (2012): 42-55.

30. Radford Elizabeth J., et al. "In utero undernourishment perturbs the adult sperm methylome and intergenerational metabolism". Science 345.6198 (2014).

31. Janssen Bram G., et al. "Placental DNA hypomethylation in association with particulate air pollution in early life". Particle and Fibre Toxicology 10.1 (2013): 22.

32. Murphy Mary M., et al. "Global assessment of select phytonutrient intakes by level of fruit and vegetable consumption". British Journal of Nutrition 112.6 (2014): 1004-1018.

33. Jiménez-Chillarón Josep C., et al. "The role of nutrition on epigenetic modifications and their implications on health". Biochimie 94.11 (2012): 2242-2263.

\section{Assets from publication with us}

- Prompt Acknowledgement after receiving the article

- Thorough Double blinded peer review

- Rapid Publication

- Issue of Publication Certificate

- High visibility of your Published work

Website: www.actascientific.com/

Submit Article: www.actascientific.com/submission.php

Email us: editor@actascientific.com

Contact us: +919182824667 